\title{
ENVIRONMENTAL REGULATION, PUBLIC PARTICIPATION AND HAPPINESS: EMPIRICAL RESEARCH BASED ON CHINESE GENERAL SOCIAL SURVEY OF 2015
}

\author{
ZHENG, Y., ${ }^{1,2}-$ YANG, R.Y. ${ }^{3 *}$ \\ ${ }^{I}$ School of Humanities, Economics, and Laws, Northwestern Polytechnical University \\ $X i$ 'an 710072, China \\ ${ }^{2}$ Education Center of MPA, Northwestern Polytechnical University, Xi'an 710072, China \\ ${ }^{3}$ College of Management and Economics, Tianjin University, Tianjin 300072, China \\ ${ }^{*}$ Corresponding author \\ e-mail: yangruoyu1993abc@163.com; phone: +86-155-1086-6322
}

(Received $3^{\text {rd }}$ Apr 2019; accepted $17^{\text {th }}$ May 2019)

\begin{abstract}
From the dual perspectives of "performance model" and "expectation model", this paper studies the influences of government regulation and public participation on satisfaction with environmental governance and individuals' happiness based on the data from the Chinese General Social Survey in 2015 (CGSS2015). By constructing the structure-equation model (SEM), it was found that: (1) both environmental regulation and public participation can significantly promote individuals' happiness, and the significance of the former is higher than that of the latter; (2) the improvement of satisfaction with environmental governance can effectively enhance individuals' happiness, and it plays an intermediary role in the relationship between environmental regulation, public participation and individuals' happiness. (3) individual characteristics also affect happiness. The economic and social status of the individuals play a positive moderating role in the relationship between environmental regulation and public participation and happiness. Therefore, we should strengthen government regulation and at the same time ensure public participation and change the "process orientation" to "problem orientation" and "result orientation" to truly improve environmental governance performance and public satisfaction. Meanwhile, the government should also pay attention to the environmental demands and living needs of the vulnerable group to realize social justice and improve individuals' happiness.
\end{abstract}

Keywords: environmental regulation, public participation, performance model, expectation model happiness

\section{Introduction}

According to previous studies, even though micro-factors such as individual characteristics (income, employment, education, marriage and so on) can explain many variations of citizens' happiness, there still remain variations that are unexplained. Happiness also can be affected by some external macro-factors, including social environment and natural environment which heavily rely on government intervention (Ott, 2010). Utilitarians point out that governments should try their best to create the greatest happiness for the greatest number of people (Veenhoven, 2010). Although many scholars are still debating on whether it should be used as the basic principle and aim for laws and public policies and questioning its feasibility and risks, the concept that individuals' happiness is an important part of value orientation has been generally recognized (Duncan, 2010; Frey and Gallus, 2013). Bhutan has already used the Gross National Happiness Index since 1972 to evaluate the performance of the government. Besides, many other countries have also promoted the application of the happiness 
index in the government management practices, such as France, the United States and China.

In recent years, environmental pollution has become a global issue, seriously affecting the health and living quality of the people around the world and decreasing their happiness. Juncal et al. studied the relationship between air pollution, climate and individuals' happiness in Spain, and found that air pollution can have various impacts on people's happiness in different aspects (Cuñado and Gracia, 2013). By utilizing the panel data of the happiness survey carried out in ten countries, Welsch provided cross-border evidence for the negative relationship between air pollution and subjective sense of happiness (Welsch, 2006); Mackerron found that the respondents will feel a strong sense of happiness when they are in a beautiful natural environment rather than a more common external environment (Mackerron and Mourato, 2013).

In this context, the influence of government environmental regulation on national happiness has become an important topic that is widely concerned by both the academic circle and the government departments. In 2016, the Chinese government announced that China has entered the " $13^{\text {th }}$ Five-Year Plan" period, and would pay high attention to environmental regulation. On $4^{\text {th }}$ January, 2016, the Central Environmental Protection Supervision Group was formally established and began to carry out environmental protection supervision in all provinces. In October 2017, President Xi of the People's Republic of China clearly pointed out that China would "construct an environmental management system led by the government, dominated by enterprises, and in which social organizations and the public are to participate (Wang and $\mathrm{Li}, 2018$ )", and pay more attention to the effective role of public participation in the environmental governance. In the previous environmental regulations, many parties have been involved, including government administration bodies and also a diversity of social organizations and people. The enhancement of the environmental governance performance in China, to a large extent, can be attributed to both the institutionalized regulatory policies and non-institutionalized public participation. Various social subjects, such as environment protection organizations, third-party agents and citizens, are all playing important roles (Dungumaro and Madulu, 2003). Among them, the most extensive participants are undoubtedly individual citizens, and the most common and direct way is participating in the environmental governance process by filing petition letters and reports and protecting their own rights through the judicial way. When a pollution incident breaks out, the direct participation of the public often plays a crucial role. Therefore, this paper intends to perform an empirical analysis of the relationships between government regulation, public participation, satisfaction with environmental governance and individuals' happiness using the data of CGSS2015.

\section{Literature Review and Hypotheses}

Improving public satisfaction and individuals' happiness has become an important goal for the government. Overall speaking, the influential factors to public service satisfaction can be divided into three categories - macro-factors, including government management and public service, meso-factors, including social organization development and public participation, and micro-factors, including personal development and personal expectation. Currently, there are few literatures focusing on the study of the influential mechanism for satisfaction with environmental governance, not to say the related empirical studies. With the improvement of people's living 
standards and the prominence of environmental pollution issues, both government departments and the public have increasing demands for environmental governance. However, satisfaction with environmental governance is a kind of subjective feeling of an individual, so it is necessary to study the micro-factors to personal perception. In the previous literatures, it can be found that the explanation models about satisfaction mainly consist of two perspectives, with one being the performance model perspective, and the other, the expectation model perspective. From the perspective of the latter, the public evaluation of government is a function of various government performances. Public satisfaction mainly depends on the performance that the government demonstrates in various aspects (Swindell and Kelly, 2000). From the perspective of the expectation model, the public evaluation of service is based on the comparison between the service quality they have truly received/felt and the one they expect. The most famous model is the service quality model (Parasuraman et al., 1988). This theory believes that satisfaction measures the gap between the performance perceived and the one expected by the public. That is to say, there is a significant positive correlation between performance and satisfaction if expectation remains unchanged (Parasuraman et al., 1991). To some extent, the improvement of satisfaction will also promote the improvement of individuals' happiness. Therefore, the government's environmental regulation and the satisfaction of public expectation will not only help improve satisfaction, but also lead to the improvement of happiness. This paper builds a new theoretical model by incorporating environmental regulation and public participation into the analytical framework and conduct in-depth research on the influencing mechanism for satisfaction with environmental governance and individuals' happiness based on these two perspectives.

\section{Environmental governance and individuals' happiness}

Environmental economists and happiness economists are all very concerned about environmental pollution problems, and they believe that in order to guarantee the happy life for the current generation and the welfare of the people in the future, it is necessary to reduce pollution and protect the natural environment (Menz, 2011). The studies carried out by previous scholars show that the environmental pollution has a negative relationship with the individuals' happiness. Welsch first analyzed air quality by measuring the pollutants such as sulfur dioxide and nitrogen dioxide, and studied the relationship between air pollution and individuals' subjective happiness using crosssectional data from 54 countries. The results show that air pollution can significantly reduce individuals' happiness (Welsch, 2002). It affects individuals' happiness through the following ways: first, air pollution, water pollution and other common environmental pollution would affect individuals' health, furthermore reducing their subjective happiness (Yang and Liao, 2017); second, environmental pollution causes inconvenience to individuals' life, thus affecting their happiness. Environmental regulation can promote economic transformation and achieve green development to a certain extent (Chen and Yang, 2018). Therefore, this paper proposes the first hypothesis:

H1: Environmental regulation has a positive impact on happiness

\section{Public participation and individuals' happiness}

In the process of environmental regulation, government regulation is indispensable, but the public is also an important force and plays an important role in environmental 
protection. Public participation makes the decisions more rational and efficient and the whole society can be mobilized to protect the environment, which is the fundamental solution to the environment protection (Yang and Chen, 2019). Public participation enables people to better express their demands and intentions and exercise their environmental rights. Therefore, in the modern society, the role of public participation is becoming increasingly prominent. In the process of environmental regulation, we often face the double troubles of "market failure" and "government failure". In this case, public participation is undoubtedly the only way to eliminate environmental pollution. In this process, the expectations of stakeholders will be better satisfied and thus the sense of happiness will be enhanced. Therefore, this paper proposes the second hypothesis:

$\mathrm{H} 2$ : Public participation has a positive impact on happiness.

\section{Environmental regulation and satisfaction with government governance}

From the perspective of the performance model, previous scholars generally believe that how the government performs determines the results of public evaluation and satisfaction (Kelly and Swindell, 2002). In a country like China, environmental protection and environmental accountability are the two most effective regulation methods. Increasing the weight of environmental protection assessment in performance assessment indices and adopting various forms of environmental accountability systems from the central government to the local government have both produced obvious effects and improved public satisfaction with environmental governance. In 2015, the Chinese government issued an outline for building a law-based government, which points out that the achievements in legal construction will also be incorporated into the index system. In recent years, the legalization of Chinese environmental regulation has been improving continually. Strengthening the legalization of environmental governance is not only beneficial to dealing with more serious environmental problems, but also conducive to the reconstruction of ecological responsibilities and the protection and realization of citizens' environmental rights. Therefore, the level of legalization of environmental governance has an influence over public's satisfaction. When the environmental governance tends to be more legalized, and the law systems more standardized, the quality of governmental regulation and service will be significantly improved, the environmental governance will enter a virtuous circle, and the public's satisfaction with environmental governance will be greatly improved (Kim and Kim, 2012). Based on this, this paper measures the degree of environmental governance by two indices - "environmental accountability" and "environmental governance legalization level", and proposes the hypothesis below:

H3: Environmental regulation has a positive impact on the satisfaction with government governance.

\section{Public participation and satisfaction with government governance}

From the prospective of the expectation model, the public satisfaction is a relative concept, which can be reflected by the gap between the actual performance and the expected one. Based on this model, previous scholars think that when the expectation is effectively satisfied, public satisfaction will be obviously improved (Parasuraman et al., 2002). In fact, public expectation is subjective and difficult to quantify. With the transformation of the government functions and the reform of administrative systems, public participation has become an effective method to express the demands and 
expectations of the public. The higher the public participation, the more easily the expectation can be satisfied. Therefore, this paper uses the effectiveness of public participation to reflect the satisfaction degree of public expectation, which consists of two dimensions: the effectiveness of the process and that of the result. The former provides the public with more channels and ways to report their environmental problems, which realizes "procedural justice". The effectiveness of the result means that the problems reported by the public can be truly solved, and that the environmental demands can be really satisfied. Ensuring the result effectiveness of public participation can help quickly solve environmental problems that have not been discovered by the government departments and cannot be solved by the market mechanism, so this realizes "outcome justice". In the real life, as a kind of political participation, petition has increasingly become an important means for citizens to interact with government departments and solve environmental problems (Tang, 2000). The process and result effectiveness of petition not only truly meets public's expectation, but also improves their satisfaction towards environmental governance. Based on this, this paper proposes the hypothesis below:

H4: Public participation has a positive impact on satisfaction with government governance.

\section{Satisfaction with government governance and individual's satisfaction}

The government has an important influence on individuals' happiness with its resources and policies. The difference in government performance is one of the most important reasons for the differences in individuals' happiness in different countries (Ott, 2011). Ott (2015) thinks that a good government protects human rights and judicial justice, alleviates social injustice and provides a good living environment and social environment for the public, thus improving individuals' happiness. The government has the power to control the system execution, make policies and allocate resources, which can have direct impacts on the market, the society and even each individual, so a standardized and effective government has positive impacts on individuals' happiness and accordingly, the improvement of the satisfaction with government governance will promote the individuals' happiness (Coggburn and Schneider, 2003). Based on this, this paper proposes the fifth hypothesis:

H5: Satisfaction with government governance has a positive impact on individuals' happiness.

\section{Intermediary role of satisfaction with government governance}

According to the above analysis, environmental regulation and public participation can help improve the satisfaction with government governance; and the satisfaction with government governance can further promote the improvement of individuals' happiness. There is a high correlation between the quality of government public service and the public's satisfaction with public service. The latter can directly reflect the former (Swindell and Kelly, 2000). The level of government public service quality also directly influences individuals' happiness. After comparing the impacts of government governance quality between the developed countries and the developing countries using the citizen satisfaction index in the world values survey (WVS), Helliwell found that in developing countries, the satisfaction with government public services has a greater impact on national happiness (Helliwell and Huang, 2008). Therefore, the satisfaction 
with government governance can be regarded as an intermediary variable. Based on this, this paper proposes the sixth hypothesis and sub-hypothesis.

H6: Satisfaction with government governance plays an intermediary role in the relationship between environmental regulation, public participation and individuals' happiness.

H6a: Satisfaction with government governance plays an intermediary role in the relationship between environmental regulation and individuals' happiness.

H6b: Satisfaction with government governance plays an intermediary role in the relationship between public participation and individuals' happiness.

\section{Moderating role of individual characteristics (economic and social status)}

Some individual characteristics, such as gender, age, education and income, would affect citizens' expectation, thus affecting the satisfaction with environmental governance and individuals' happiness. According to previous studies, income can reflect a person's economic status, and there is a certain positive correlation between income and subjective happiness (Shields et al., 2009). Higher education background can increase individual's independence and help form good interpersonal relations, and promote public participation and improvement of happiness (Chen, 2012). Besides, based on the "profit-cost" allocation, the group with higher economic status enjoys more profits generated at the expense of environment, but they use their economics advantages to pass on the environmental consequences and environmental governance accountability to the relatively more vulnerable groups. However, the poor are less able to migrate than the rich and less able to avoid environmental pollution. Generally speaking, the group with higher income and education background has more ways to express their claims and participate in the public. Therefore, this paper uses economic income and education level to measure the economic and social status of individual characteristics, and puts forward the following hypotheses:

H7: The higher the economic and social status, the more significant the positive impact of environmental regulation on individuals' happiness.

H8: The higher the economic and social status, the more significant the positive impact of public participation on individuals' happiness.

Above all, this paper mainly studies the impacts of environmental regulation and public participation on individuals' happiness. During the process, satisfaction with government governance is an intermediate variable, while individual income and education level are moderating variables. The theoretical model constructed according to the research hypothesis is shown in Figure 1. Since the age and gender of individuals also have impacts on happiness (Cai et al., 2018), this paper takes these two factors as control variables for analysis in the data processing process.

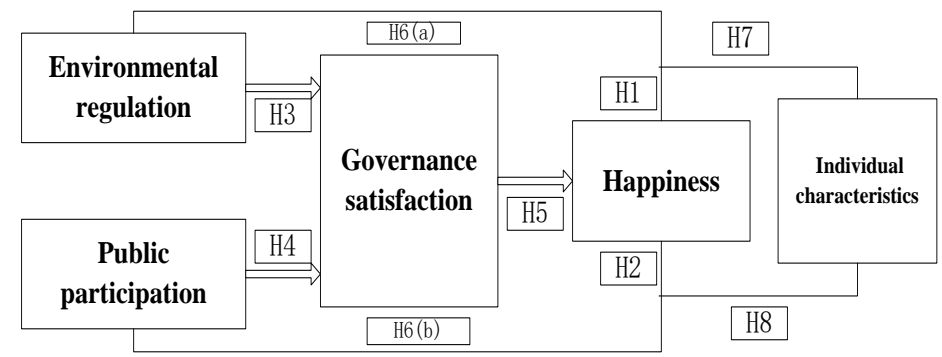

Figure 1. Variable models in this paper 


\section{Materials and Methods}

\section{Materials}

In this paper, environmental accountability and the environmental regulation legalization level are used to measure the government environment regulation. In the CSSS survey, there are six modules-A, B, C, D, E and F, in which F is the "legal module", consisting of questions on government accountability and regulatory compliance, with environmental regulation sub-questions. The corresponding original questions are "Will the government be held accountable when the government leaders blindly pursue output value and neglect the supervision on enterprise pollution discharge, resulting in environment deterioration?" and "How is the government's compliance with laws when it is handling environmental pollution?". The higher the score, the stronger the government's environmental regulation and the higher the level of legalization.

In terms of public participation, when an individual is facing environmental pollution issues, the common way to safeguard his or her rights is to file a petition letter. With the gradual improvement of the environmental protection petition system in China, petition now plays an increasingly important role in environmental regulation. In the real life, there are two requirements to be met if environmental pollution problems can be solved by petition: first, the public's petition rights have been safeguarded; second, the environmental problems reported by the public have been effectively solved. This paper measures public participation from the two dimensions: first, "will the petition be blocked" (process effectiveness), second, "can the petition solve your problem" (result effectiveness). In the CGSS survey module F, the questions related to petition have been set. The original questions are respectively "Do you agree with the following: petition will not be blocked" and "Do you agree with the following: petition can solve the problem". The higher score is, the higher degree of public participation there will be.

The satisfaction with government governance is covered by question B15 in the module B of the CGSS questionnaire. The original question is "Are you satisfied with the government's performance in environmental protection?" This paper determines the satisfaction degree of environmental governance based on this. In the original questionnaire, the corresponding ratings are "very satisfied--satisfied--neutral-dissatisfied--very dissatisfied", with a score from 1 to 5 . This paper uses the negative numbers, so that the higher the score is, the higher the satisfaction degree will be.

Concerning the happiness and individual's economic social status, there are relative questions in module $\mathrm{A}$ of the CGSS questionnaire. The question about happiness is "Generally speaking, are you happy?" In the choices, 1 represents "very unhappy", and 5 "very happy". The higher the score is, the happier the respondent is. The income in individual characteristics refers to the actual income of the respondent. The education background is divided into 13 grades, with 1 representing "illiterate", 13 "Postgraduate and above". The higher the score is, the higher the education level is. In control variables, age is 2018 minus the year of birth. Men are assigned with a value of 1 , while women, 2.

\section{Study samples and data sources}

The related variable data in this paper are mainly from the survey results of Chinese General Social Survey in 2015 (CGSS2015), which is the first national, comprehensive, continual and large-scale social investigation program in China. The purpose is to 
regularly and systematically collect data of Chinese people and various aspects of Chinese society, summarize the long-term trends of social changes, explore social issues of great theoretical and practical significance, promote the openness and sharing of domestic social science research and provide data for government decision-making and international comparative research. Since 2003, it has carried out sample surveys among 10,000 families in 31 provinces in China annually. The lasted survey was carried out in 2015 with the data released in January 2018. The survey comprehensively measures the living and development status of urban and rural residents, public's satisfaction with social governance, and individual's perception of the government's legal construction. The samples are large in size and widely distributed in China, which is suitable for the correlation analysis in this study. In the specific analysis process, some data have been processed, and the choices "unable to answer", "refuse to answer", "don't know" and "not applicable" are regarded as missing values. Variable measurement and data processing are shown in Table 1 .

Table 1. Variable measurement and data processing

\begin{tabular}{|c|c|c|c|}
\hline Category & Variable & Survey Item & Illustrate \\
\hline \multirow[t]{2}{*}{$\begin{array}{c}\text { Independent } \\
\text { variable }\end{array}$} & $\begin{array}{l}\text { Environmental } \\
\text { regulation }\end{array}$ & $\begin{array}{l}\text { 1: Will the government be asked to take the } \\
\text { responsibility when the government leaders } \\
\text { exclusively pursue output value and neglect } \\
\text { the supervision for the enterprise pollution } \\
\text { discharge which resulted in the environment } \\
\text { deterioration? } \\
\text { 2: How is the government's level of handling } \\
\text { environmental pollution in accordance with } \\
\text { law }\end{array}$ & $\begin{array}{l}\text { The higher the score is, the } \\
\text { stronger the government's } \\
\text { environmental regulation and } \\
\text { the higher the level of } \\
\text { legalization will be. }\end{array}$ \\
\hline & Public participation & $\begin{array}{l}\text { 1: Will be the petition blocked } \\
\text { 2: Can the petition solve your problem }\end{array}$ & $\begin{array}{l}\text { The higher score means the } \\
\text { higher degree of public } \\
\text { participation. }\end{array}$ \\
\hline \multirow{2}{*}{$\begin{array}{l}\text { Moderating } \\
\text { variable }\end{array}$} & \multirow{2}{*}{$\begin{array}{l}\text { Individual } \\
\text { features }\end{array}$} & & $\begin{array}{l}\text { The bigger the value, the higher } \\
\text { the income. }\end{array}$ \\
\hline & & 2: Educational level. & $\begin{array}{l}\text { The higher the value, the higher } \\
\text { the degree }\end{array}$ \\
\hline $\begin{array}{l}\text { Intermediary } \\
\text { variable }\end{array}$ & Satisfaction & $\begin{array}{l}\text { Are you satisfied with the government's } \\
\text { performance in environmental protection? }\end{array}$ & $\begin{array}{c}\text { The higher the value is, the } \\
\text { higher the satisfaction degree } \\
\text { is. }\end{array}$ \\
\hline \multirow{2}{*}{ Control variable } & Gender & Gender & Male is 1 , female is 2 \\
\hline & Age & Date of birth & 2018 minus date of birth \\
\hline $\begin{array}{l}\text { Dependent } \\
\text { variable }\end{array}$ & Happiness & Generally speaking, are you happy & $\begin{array}{l}\text { The higher the value, the } \\
\text { higher the degree. }\end{array}$ \\
\hline
\end{tabular}

In the specific survey process, module A is the core, and module B is the "ten-year review" module, in which all questions are mandatory to the respondents. The samples for dependent variables and control variables in this paper cover more than 10,000 families. However, module F module only conducted a sampling survey among more than 3,000 households. After data sorting, it was found that only 3,777 people were required to complete this section. Considering there are missing values, the effective sample size would be even less than 3,777. Therefore, only more than 3,000 samples are used for the independent variables in this paper. 


\section{Results}

\section{Reliability test and single-dimension analysis}

This study adopts the software SPSS 21.0 and AMOSS 21.0, respectively, to test the reliability and validity structures of the choices for measurement, and uses the CITC and reliability analysis methods to analyze the reliability of the choices, with CITC $>0.3$ and Cronbach's $\alpha>0.7$ as the criteria. The survey choices in the table correspond to those in the questionnaire. The analysis results show that all the CITC values are greater than 3, and that the overall Cronbach's $\alpha$ parameters are all greater than 0.7 , which meet the reliability requirements, and thus the choices can be applicable to future analysis.

Before analyzing the factors, it is necessary to confirm whether there are common factors in the data. Bartlett sphere test is used to test whether the related matrix is the unit matrix or not, which indicates the suitability of the factor model. The KMO (Kaiser-Meyer-Olkin) value indicates whether the selected samples are suitable or not and also whether the information is suitable for factor analysis. The KMO value ranges from 0 to 1 . It is generally believed that a value above 0.9 means the sample is very suitable, that $0.8-0.9$, the sample is quite suitable, that $0.7-0.8$, the sample is suitable, and that a value below 0.5 , the sample is not suitable. The probability P-value of the Bartlett sphere test should be less or equal to the significance level. Table 2 shows that the KMO values of all the variables are greater than 0.7 in this study, which is suitable for future study.

Table 2. Results of KMO and Bartlett's test

\begin{tabular}{c|c|c|c|c|c|c}
\hline \multirow{2}{*}{ Variable } & \multirow{2}{*}{ Dimension } & \multirow{2}{*}{ KMO } & \multicolumn{3}{|c|}{ Bartlett's Test } & \multirow{2}{*}{ Suitability } \\
\cline { 4 - 7 } & & & Chi-square & Freedom & P & \\
\hline \multirow{2}{*}{ Independent variable } & Environmental regulation & .789 & 570.197 & 6 & .000 & Fit \\
\cline { 2 - 7 } & Public participation & .779 & 519.290 & 6 & .000 & Fit \\
\hline Intermediary & Satisfaction & .886 & 1065.282 & 15 & .000 & Very fit \\
\hline Moderating1 & Income & .715 & 299.969 & 6 & .000 & Fit \\
\hline Moderating2 & Educational level & .723 & 308.471 & 6 & .000 & Fit \\
\hline
\end{tabular}

In order to further guarantee the validity of the scale, this study carries out exploratory factor analysis (EFA) to understand whether the number and content of levels in the scale are consistent with those of the operational definition. The results show that the load values of the two factors extracted from the independent variables meet the analysis requirements and the overall validity is acceptable.

\section{Descriptive statistical analysis}

Table 3 is the descriptive statistical analysis results of the data after being processed. Since there are only 3,777 respondents for module F, this paper carries out two descriptive statistical analysis based on the related variables, including the overall sample statistical analysis, and the subsample statistical analysis for the answers only in module F. Among the variables, the value of the environmental governance legalization is greater than that of environmental accountability, which shows that the respondents generally believe that the level of legalization in environmental governance is higher than the level of accountability. But both values are lower than 3, which shows that neither factor is at a high level. 
Table 3. Results of descriptive statistic analysis

\begin{tabular}{c|c|c|c|c|c}
\hline Measurement Item (Variable Code) & N & Min & Max & Average & Standard Deviation \\
\hline Environmental Accountability (EC) & 3236 & 1 & 5 & 2.63 & 1.12 \\
Governance Legalization (EL) & 3641 & 1 & 5 & 2.95 & 0.88 \\
Petition can't be Blocked (P1) & 3337 & 1 & 5 & 2.61 & 1.06 \\
Petition can Solve Problem (P2) & 3341 & 1 & 5 & 2.73 & 1.06 \\
\hline The Whole Sample & & & & & \\
\hline Personal Annual Gross Income (I1) & 10363 & 0 & 9999990 & 32805.33 & 205840.55 \\
Education Level (ED1) & 10939 & 1 & 13 & 4.87 & 3.11 \\
Government Governance Satisfaction (S1) & 10820 & -1 & -5 & -2.7 & 0.92 \\
Gender(G1) & 10968 & 1 & 2 & 1.53 & 0.50 \\
Age (A1) & 10968 & 21 & 98 & 53.4 & 16.90 \\
Individuals' happiness (H1) & 10953 & 1 & 5 & 3.87 & 0.821 \\
\hline Sub-sample & & & & & \\
\hline Personal Annual Gross Income (I2) & 3578 & 0 & 2000000 & 27792.19 & 59698.21 \\
Education Level (ED2) & 3767 & 1 & 13 & 4.82 & 3.07 \\
Government Governance Satisfaction (S2) & 3739 & -1 & -5 & -2.7 & 0.91 \\
Gender (G2) & 3777 & 1 & 2 & 1.53 & 0.50 \\
Age (A2) & 3777 & 21 & 98 & 53.22 & 17.07 \\
Individuals' happiness (H2) & 3735 & 1 & 5 & 3.81 & 0.81 \\
\hline \multicolumn{2}{r}{}
\end{tabular}

In the whole samples, the value of the variable individuals' happiness is 3.87 , and $59.97 \%$ of the respondents are in the "relatively happy" status. The maximum score for the satisfaction with government environmental governance is -1 , the minimum value -5 , and the average -2.7 . The choice with a score of -2 is "satisfied", and $42.0 \%$ of the respondents chose it. The choice with a score of -3 is "neutral", which $32.7 \%$ of the respondents chose. It can be clearly seen that the majority citizens are satisfied with the government's environmental governance work, but the average value of happiness is greater than that of satisfaction. Concerning the individual characteristics, the average amount of annual income per capita was $32805.33 \mathrm{RMB}$, and the standard deviation was as high as $205840.55 \mathrm{RMB}$, which shows the respondents have great income disparities. According to the official data from the national bureau of statistics, the per capita disposable income of Chinese residents in 2014 was 20167 RMB. So overall, the income level of the respondents is higher than the national average. In terms of education, the average score is 4.87. In the original questionnaire, a score of 5 corresponds to vocational high school, so the average score means that the education level of the respondents is between junior and senior high school, which is consistent with the actual situation - nine-year compulsory education - in China. However, the education level of the urban and rural residents as a whole still remains to be improved compared with that in western developed countries.

The extreme, average and standard deviation of the mediating variables and dependent variables in the sub-samples are generally consistent with those in the overall samples. The gender distribution in the system variable is consistent with that in the overall samples, and the male-female ratio is relatively balanced. The maximum personal annual income in the moderating variable is 2 million RMB, the average and the standard deviation are respectively 27792.19 RMB and 59698.21 RMB which are both lower than the results in the overall samples. This shows that the individual income disparity of the sub-samples is relatively small, which is consistent with the actual situation. The highest education level in the moderating variable is basically consistent with the overall situation in the overall samples. This indicates that the sub-samples are highly representative and suitable for further analysis. 


\section{Hypothesis verification results}

Table 4 shows the results of multiple regression analysis involving environment regulation, public participation, satisfaction with government governance as well as individuals' happiness and other variables.

Table 4. Results of multiple regression analysis

\begin{tabular}{|c|c|c|c|c|c|c|c|c|c|c|c|}
\hline \multirow{2}{*}{$\begin{array}{c}\begin{array}{c}\text { Variable } \\
\text { (Code) }\end{array} \\
\begin{array}{c}\text { Variable } \\
\text { (Code) }\end{array}\end{array}$} & \multicolumn{2}{|c|}{$\begin{array}{l}\text { Governance } \\
\text { satisfaction }\end{array}$} & \multicolumn{9}{|c|}{ Individuals' happiness } \\
\hline & Model1 & Model2 & Model3 & Model4 & Model5 & Model6 & Model7 & Model8 & Model9 & Model10 & Model11 \\
\hline Gender (G2) & -0.038 & -.034 & -.033 & -.039 & -.038 & -.038 & -.035 & -.038 & -.038 & -.038 & -.037 \\
\hline Age (A2) & $0.002^{*}$ & $0.002 *$ & $0.002 *$ & $0.002 *$ & $0.002 *$ & $0.002 *$ & $0.002 *$ & $0.002 *$ & $0.002 *$ & $0.002 *$ & $0.002 *$ \\
\hline $\begin{array}{l}\text { Environmental } \\
\text { regulation } \\
\text { (ER) }\end{array}$ & $0.192 * * *$ & & $0.203^{* *}$ & & & $0.179^{*}$ & & $0.215^{* * *}$ & & $0.207 * * *$ & \\
\hline $\begin{array}{c}\text { Public } \\
\text { participation } \\
\text { (PP) } \\
\end{array}$ & & $0.083^{* *}$ & & $0.091^{* *}$ & & & $.087^{*}$ & & $0.145^{* * * *}$ & & $0.104 * * *$ \\
\hline S2 & & & & & $1.018^{* *}$ & $1.003^{* *}$ & $1.009 *$ & & & & \\
\hline ER*I2 & & & & & & & & $.162 * * *$ & & & \\
\hline $\mathrm{PP} * \mathrm{I} 2$ & & & & & & & & & $0.104 * *$ & & \\
\hline ER*ED2 & & & & & & & & & & $.151 * * *$ & \\
\hline PP*ED2 & & & & & & & & & & & $0.101 * *$ \\
\hline $\mathrm{F}$ & $28.809^{* * *}$ & $29.756^{* * *}$ & $30.524 * * *$ & $31.535^{* * *}$ & $31.783 * *$ & $32.094 * *$ & $32.656^{* * *}$ & 33.821 *** & $33.804 * * *$ & $33.719 * * *$ & $33.699 * * *$ \\
\hline $\mathrm{R}^{2}$ & .14 & 0.16 & 0.15 & .14 & .16 & 0.14 & 0.15 & .19 & .19 & .18 & .18 \\
\hline
\end{tabular}

Note: $* * * * *$ and $*$ are significant at the statistical levels of $0.01,0.05$, and 0.1 respectively

Model 1 and model 2 respectively focus on the impacts of environmental regulation and public participation on satisfaction with government governance. Among the control variables, gender has no significant impact on satisfaction with government environmental governance, but age is positively correlated with satisfaction with government environmental governance, indicating that young people are less satisfied compared with elder people. Both environmental regulation and public participation can positively promote the improvement of satisfaction with government governance, which verifies hypothesis 3 and hypothesis 4 , and the significance of government regulation is higher than that of public participation. Model 3 and model 4 show that gender has no significant impact on individuals' happiness, and age is positively correlated with happiness, indicating that compared with young people, elder people are happier. Both environmental regulation and public participation have significant positive impacts on individuals' happiness, which verifies hypothesis 1 and hypothesis 2 , and the coefficient of government regulation is higher than that of public participation. Model 5 reflects that satisfaction with government governance has a positive impact on happiness, which verifies hypothesis 5 .

Model 6 shows that the impact of the independent variable environment regulation on individuals' happiness is obviously reduced after the satisfaction with government governance is added, which reflects that there is a significant partial mediating effect between environmental regulation and individuals' happiness; model 7 also shows that the impact of the independent variable public participation on individuals' happiness is obviously reduced after the satisfaction with government governance is added, which reflects that there is a significant partial mediating effect between public participation and individuals' happiness. Based on the above analysis, hypothesis $6 \mathrm{a}$ and 
hypothesis $6 \mathrm{~b}$ are also verified. Model 8 shows the impact of the mutual interaction between environmental regulation and personal income on individuals' happiness, and compared with that in model 3, the significance of environmental regulation is improved. Module 9 shows the impact of the interaction between public participation and personal income on individuals' happiness, and the significance of public participation is improved when compared with that in, module 4, which verifies hypothesis 7. Model 10 shows the impact of environmental regulation and education interaction on individuals' happiness. Compared with that in model 3, the impact of environmental regulation is significantly enhanced. Model 11 shows the impact of the interaction between public participation and education on individuals' happiness. Compared with that in model 4 , the impact of public participation is significantly enhanced. Therefore, education level also has a positive moderating effect, proving Hypothesis 8.

\section{Robustness test}

In fact, there are many forms of public participation in environmental governance and right relief. Besides petition, judicial litigation is undoubtedly a relatively common way. In order to verify the reliability of the results in Table 4, this paper replaces the two questions used in the above questionnaire to measure the "effectiveness of public participation" and replaces the questions related to petition with those related to environmental lawsuit. In module F in the CGSS2015 questionnaire, questions F10 and F11 cover the timeliness and the enforcement effort of the court when the public participates in environmental governance through litigation, which could be used to measure the process and result effectiveness of public participation. The original question F10 is "If there is an enterprise nearby discharging waste gas or sewage in violation of regulations, which results in serious harm to the health of the residents, how soon do you think the court will make a decision if you file a lawsuit, asking the above enterprise to compensate for loss?" The higher the score is for the question, the stronger the process effectiveness of public participation will be. The original question for F11 is "If the court's ruling is in favor of the residents, but the enterprise doesn't execute the ruling and the resident applies for compulsory execution, how do you think the execution will go?" The higher the score is for the question, the stronger the process effectiveness of public participation will be. Therefore, this paper covers the two dimensions of the variable "public participation effectiveness" with the above two questions to test its robustness. Overall, the results are generally consistent with Table 4 . Therefore, the models in this paper have strong robustness.

\section{Discussion}

\section{Improving the government environmental governance and the effectiveness of public participation is both beneficial to improving satisfaction and happiness}

The study in this paper indicates that guaranteeing the effectiveness of environmental accountability and expanding the ways of public participation can effectively solve the environmental pollution issues, and improve the satisfaction with government environmental governance and individuals' happiness. Therefore, we should further improve the mechanism of public participation in environmental governance and formulate the legal system at the macro level to protect the right of the public to report 
problems and claim for compensation, encourage the development of environmental protection organization and take social organizations as the bridge between the government and the public to effectively carry out environmental regulation at the meso level, and set up hotlines and email boxes for reporting of environmental protection problems at the micro level so that individuals can more actively participate in the environmental regulation process.

\section{Satisfaction with government governance plays an intermediary role between} environmental regulation, public participation and individuals' happiness

Besides strengthening government regulation and expanding the ways for public participation, we should also make effort to improve effectiveness and truly solve environmental problems. We should shift the focus from "process orientation" and "input orientation" to "problem orientation" and "result orientation". After receiving reports and feedbacks from the public, practical implementation plans should be put forward to truly solve environmental problems. Only when the public's requirements are fully met, can we promote the improvement of the environmental governance system and realize "process justice" and "outcome justice", so as to ensure environmental protection development and improve individuals' happiness.

Individual's economic and social status plays a positive moderating role in the relationship among environmental regulation, and public participation and individuals' happiness

Overall, people with higher income and education level have more ways to express their own demands, higher awareness of safeguarding their environment rights, as well as more ways for public participation. The higher the income is, the more significant the impact of environmental regulation and public participation will be on individuals' happiness. This requires the government to apply various methods to improve individuals' happiness according to the real situations, pay attention to the environmental demands and living requirements of the group with lower income and education background. The group with higher economic status enjoys more profits generated at the expense of the environment, but they can utilize their economics advantages to pass on the environmental consequences and environmental governance accountability to the relatively more vulnerable groups. Therefore, the government should adjust public finance in the second distribution and allocate more public expenditures to the vulnerable groups so as to meet their demands, promote social justice and further improve individuals' happiness.

\section{Conclusions}

The results of the empirical study show that both reinforcing government accountability and improving the environmental governance legalization level can effectively improve the satisfaction with environmental governance and individuals' happiness. We should make full use of environmental accountability in the future, and increase the number and weights of environmental performance indices in the government management performance system, intensify accountability and implement environmental regulatory policies. At the same time, we should make environmental governance more legalized and standardized, set up specific laws and regulations on 
environment regulation, punishment and safeguarding of rights, improve relevant systems and mechanisms and establish a sound environment regulation system.

Overall, the score of satisfaction with government environmental governance is lower than the average score of individuals' happiness. The satisfaction with government environmental governance has positive impacts on individuals' happiness, and plays an intermediary role between environmental regulation, public participation and individuals' happiness. It acts on individuals' happiness in both objective and subjective ways. Environmental governance can solve environmental pollution issues and enhance the public's satisfaction towards public service, thus improving individuals' happiness. Therefore, we should focus on improving the efficiency of government environmental governance, meeting public needs, and improving environmental governance satisfaction.

Individual's economic and social status plays a positive moderating role in the relationships between environmental regulation, public participation and individuals' happiness. It is clear that the higher the income is, the greater the effect of the independent variable will be on individual's happiness, education level also has a positive moderating effect. Therefore, the government should also pay attention to taking different measures according to the needs of different groups of people in the process of environmental governance.

This study has certain limitations due to limited time and space. The questionnaire is only issued in China and only reflects the situation in the year of 2015 . We can issue questionnaires on a larger scale in the future, Conducting cross-country research and multinational comparison. It is also possible to conduct follow-up surveys and collect data for many years, analyze and study years of panel data. Research the influences of government regulation and public participation on satisfaction with environmental governance and individuals' happiness in different countries at different times.

Acknowledgements. This research was funded by "Humanities and Social Science Foundation of Ministry of Education of China" (grant number 19YJCZH267) and supported by "the Fundamental Research Funds for the Central Universities" (grant number 31020170QD107), and by Major theoretical and practical research projects in the social sciences of Shaanxi Province (grant number 2019C152).

\section{REFERENCES}

[1] Cai, J., Zhang, L., Zhao, Y., Coyte, P. C. (2018): Psychological mechanisms linking county-level income inequality to happiness in China. - International Journal of Environmental Research and Public Health 15: 2667.

[2] Chen, W. (2012): How education enhances happiness: comparison of mediating factors in four east asian countries. - Social Indicators Research 106(1): 117-131.

[3] Chen, W., Yang, R. (2018): Evolving temporal-spatial trends, spatial association, and influencing factors of carbon emissions in mainland China: Empirical analysis based on provincial panel data from 2006 to 2015. - Sustainability 10(8): 2809.

[4] Coggburn, J. D., Schneider, S. K. (2003): The relationship between state government performance and state quality of life. - International Journal of Public Administration 26(12): 1337-1354.

[5] Cuñado, J., Gracia, F. (2013): Environment and happiness: New evidence for Spain. Social Indicators Research 112(3): 549-567.

[6] Duncan, G. (2010): Should happiness-maximization be the goal of government. - Journal of Happiness Studies 11(2): 163-178. 
[7] Dungumaro, E. W., Madulu, N. F. (2003): Public participation in integrated water resources management: The case of Tanzania. - Physics \& Chemistry of the Earth Parts A/b/c 28(20): 1009-1014.

[8] Frey, B. S., Gallus, J. (2013): Political economy of happiness. - Applied Economics 45(30): 4205-4211.

[9] Helliwell, J. F., Huang, H. (2008): How's your government? International evidence linking good government and well-being. - British Journal of Political Science 38(04): $85-108$

[10] Kelly, J. M., Swindell, D. (2002): A multiple-indicator approach to municipal service evaluation: correlating performance measurement and citizen satisfaction across jurisdictions. - Public Administration Review 62(5): 610-621.

[11] Kim, S., Kim, D. (2012): Does government make people happy: Exploring new research directions for government's roles in happiness. - Journal of Happiness Studies 13(5): 875-899.

[12] Mackerron, G., Mourato, S. (2013): Happiness is greater in natural environments. Global Environmental Change 23(5): 992-1000.

[13] Menz, T. (2011): Do people habituate to air pollution? Evidence from international life satisfaction data. - Ecological Economics 71: 211-219.

[14] Ott, J. (2010): Greater Happiness for a greater number: Some non-controversial options for governments. - Journal of Happiness Studies 11(5): 631-647.

[15] Ott, J. C. (2011): Government and happiness in 130 nations: good governance fosters higher level and more equality of happiness. - Social Indicators Research 102(1): 3-22.

[16] Ott, J. (2015): Impact of size and quality of governments on happiness: Financial Insecurity as a key-problem in market-democracies. - Journal of Happiness Studies 16(6): 1639-1647.

[17] Parasuraman, A., Zeithaml, V. A., Berry, L. L. (1988): SERVQUAL: A multiple-item scale for measuring consumer perceptions of service quality. - Journal of Retailing 64(1): $12-40$.

[18] Parasuraman, A., Berry, L. L., Zeithaml, V. A. (1991): Refinement and reassessment of the SERVQUAL scale. - Journal of Retailing 67(8): 1463-1467.

[19] Parasuraman, A., Berry, L. L., Zeithaml, V. A. (2002): Refinement and reassessment of the SERVQUAL scale. - Journal of retailing 67(4): 114.

[20] Shields, M. A., Price, S. W., Wooden, M. (2009): Life satisfaction and the economic and social characteristics of neighborhoods. - Journal of Population Economics 22(2): 421443.

[21] Swindell, D., Kelly, J. M. (2000): Linking citizen satisfaction data to performance measures. - Public Performance \& Management Review 24(1): 30-52.

[22] Tang, X. (2010): Reforms in the petition letter and visit system of China and construction of a harmonious society. - Frontiers of Law in China 5(1): 77-90.

[23] Veenhoven, R. (2010): Greater happiness for a greater number. - Journal of Happiness Studies 11(5): 605-629.

[24] Wang, M., Li, S. (2018): Understanding social governance model and a better life value from the report of 19th national congress of the communist party of China. - Chinese Public Administration (3): 60-63.

[25] Welsch, H. (2002): Preferences over prosperity and pollution: Environmental valuation based on happiness surveys. - Kyklos 55(4): 473-494.

[26] Welsch, H. (2006): Environment and happiness: Valuation of air pollution using life satisfaction data. - Ecological Economics 58(4): 801-813.

[27] Yang, R., Liao, Z. (2017): PM2.5 with five pollutants, environmental management, and tuberculosis evidence from four Chinese municipalities. - Boletín de Malariologíay Salud Ambiental 57(2): 58-70. 
[28] Yang, R., Chen, W. (2019): Spatial Correlation, Influencing Factors and Environmental Supervision on Mechanism Construction of Atmospheric Pollution: An Empirical Study on $\mathrm{SO}_{2}$ Emissions in China. - Sustainability 11(6): 1742. 